\title{
Derechos personalísimos y autonomía progresiva del menor de edad en Argentina: sus derechos a la intimidad, al honor y a la imagen
}

\author{
Personal rights and progressive autonomy of minors in Argentina: \\ their rights to privacy, honor and image
}

\author{
María Bibiana Nieto \\ Universidad Católica Argentina \\ ORCID: 0000-0001-7167-4545 \\ Correo: bnieto@uca.edu.ar \\ Recibido: 13/12/2019
}

Aceptado: 28/05/2020

\section{Resumen:}

El Código Civil y Comercial de la Nación, vigente en Argentina desde 2015, establece que, en principio, los menores de 18 años ejercen sus derechos a través de sus representantes legales. Sin embargo, al adoptar el sistema de autonomía progresiva, los menores pueden realizar por sí mismos los actos que la ley establece, cuando han adquirido edad y grado de madurez suficiente. En este trabajo se examina la especial protección de los derechos personalísimos del menor, y el despliegue del principio de autonomía progresiva en el ámbito del ejercicio de los derechos de la personalidad, poniendo énfasis en los derechos a la intimidad, al honor y a la imagen.

Palabras clave: menores de edad; derechos personalísimos; autonomía progresiva; intimidad; imagen.

\begin{abstract}
:
The Civil and Commercial Code of the Nation, in force in Argentina since 2015, establishes that, in principle, children under 18 exercise their rights through their legal representatives. However, by adopting the progressive autonomy system, minors can perform the acts established by law when they have acquired enough age and maturity. This paper examines the special protection of the child's personal rights and the deployment of the principle of progressive autonomy in the field of the exercise of personality rights, with emphasis on the rights to privacy, honor and image.
\end{abstract}

Keywords: minors; personal rights; progressive autonomy; privacy; image. 


\section{Introducción}

Los derechos personalísimos, derechos subjetivos inherentes a la persona humana, requieren capacidad de ejercicio para su disposición. El Código Civil y Comercial de la Nación (CCC), vigente en Argentina desde agosto de 2015 (Ley 26994), ${ }^{1}$ establece que, en principio, los menores de 18 años son incapaces y ejercen sus derechos a través de sus representantes legales. Sin embargo, al adoptar el sistema de autonomía progresiva, se exceptúan de la representación, y los menores pueden realizar por sí mismos los actos que la ley establece, cuando han adquirido edad y grado de madurez suficiente.

Este trabajo se propone examinar la especial protección de los derechos personalísimos del niño y el despliegue del principio de autonomía progresiva en el ámbito del ejercicio de los derechos de la personalidad del menor de edad, poniendo especial énfasis en los derechos a la intimidad, al honor y a la imagen.

Teniendo en cuenta que los casos que rige la legislación del Derecho privado deben ser resueltos de acuerdo con las leyes que resulten aplicables, interpretándolas conforme a la Constitución Nacional y a los tratados de derechos humanos suscriptos por Argentina (CCC, art. 1), el presente trabajo comienza analizando las normas constitucionales y legales referida a los derechos de los niños, niñas y adolescentes.

Posteriormente, se aborda la regulación de los derechos personalísimos en general, para luego tratar la protección reforzada de los derechos a la intimidad, al honor y a la imagen del menor de edad.

Seguidamente, se individualiza a los sujetos legitimados para exigir el cese de la perturbación o ataque y/o la reparación del daño en caso de lesiones potenciales o actuales a los derechos personalísimos a la intimidad, al honor y a la imagen del niño.

A continuación, se detallan las normas que contemplan la autonomía progresiva en el ejercicio de los derechos del menor de edad establecidas en el CCC. Dentro de este apartado, se estudia primero el ejercicio de los derechos a la vida y a la integridad física vinculados a la salud y, en segundo lugar, el ejercicio de los derechos a la intimidad y a la imagen. Finalmente, se presentan las conclusiones.

\footnotetext{
${ }^{1}$ Sustituyó a los códigos civil y comercial de la Nación que, con diversas reformas y leyes complementarias, imperaron desde fines del siglo XIX hasta el 1 de agosto de 2015, fecha en la cual entró en vigor.
} 


\section{Derechos de los niños, niñas y adolescentes}

Los niños, en cuanto son sujetos de derecho, gozan de todos los derechos humanos compatibles con su condición de menores de edad, reconocidos en nuestro ordenamiento jurídico. Y dentro del marco normativo aplicable a los niños, la norma de mayor jerarquía e importancia es la Convención sobre los derechos del niño (CDN, Ley 23849, 1990) ${ }^{2}$ ya que regula específicamente los derechos de todas las personas humanas menores de edad. ${ }^{3}$ La CDN manifiesta que "el niño por su falta de madurez física y mental, necesita protección y cuidados especiales, incluso la debida protección legal, tanto antes como después del nacimiento" (CDN, Preámbulo, párr. 9). También reconoce que la familia por ser el mejor lugar para su crecimiento y bienestar, debe recibir por parte de los Estados la protección y asistencia necesarias para poder asumir sus responsabilidades (CDN, Preámbulo, párr. 5). En este sentido, los Estados parte se comprometen a respetar las responsabilidades, derechos y deberes de los padres, tutores o encargados legalmente del niño (CDN, art. 3,2).

En el artículo 2, la CDN plasma el principio de igualdad y no discriminación, que exige a los Estados firmantes garantizar a todos los niños, independientemente de cualquier otra consideración, el goce de los derechos reconocidos en ella.

En el artículo 3.1, la CDN consagra el principio del interés superior del niño como criterio para determinar el contenido de cualquier decisión en la que esté involucrado un menor de edad. En los artículos 5 y 12 recepta el principio de autonomía progresiva en el ejercicio de los derechos de los menores de edad. En efecto, el artículo 5, al disponer que los Estados deben respetar a los padres —o a quienes los sustituyan legítimamente-, en el ejercicio de sus responsabilidades, señala que estos deben dar al niño dirección y orientación teniendo en cuenta la evolución de sus facultades, en orden al ejercicio de sus derechos. (CDN, art. 5). Y el artículo 12, determina que el niño que posee discernimiento debe ser escuchado y su opinión tenida en cuenta, en toda cuestión que lo involucre. Y

\footnotetext{
${ }^{2}$ Argentina aprobó la CDN por Ley 23849, sancionada el 27 de septiembre de 1990 y promulgada de hecho, el 16 de octubre de 1990. Posteriormente la reforma constitucional de 1994, en su art. 75, inc. 22, la incorporó a la Constitución -junto a otros tratados de derechos humanos- otorgándole jerarquía constitucional. En el mencionado inciso se dice que "en las condiciones de su vigencia, tienen jerarquía constitucional, no derogan artículo alguno de la primera parte de esta Constitución y deben entenderse complementarios de los derechos y garantías por ella reconocidos".

${ }^{3}$ Argentina, al ratificar la CDN, formuló en la ley de aprobación la siguiente reserva al artículo 1: "el mismo debe interpretarse en el sentido que se entiende por niño todo ser humano desde el momento de la concepción y hasta los 18 años".
} 
especifica el derecho del menor a ser escuchado, directamente, o por medio de un representante o un órgano adecuado en todos los procedimientos judiciales o administrativos que lo atañan (CDN, art. 12).

En lo referente a la hermenéutica del tratado, la CDN, en su artículo 41, establece la prevalencia de cualquier disposición de derecho internacional o interno que sea más conducente a la realización de los derechos de los menores (CDN, art. 41).

En conformidad con lo dispuesto en la CDN, el Congreso Nacional Argentino sancionó la Ley 26061 de Protección Integral de Derechos de Niñas, Niños y Adolescentes (2005) que, a su vez, derogó el régimen de patronato que contenía la Ley 10.903 (1919).

El artículo $1^{\circ}$ de la ley 26061 señala que tiene por objeto proteger y garantizar a los niños, niñas y adolescentes (NNA), el ejercicio y disfrute pleno, efectivo y permanente de los derechos específicos existentes en el ordenamiento jurídico nacional y en los tratados internacionales.

La norma es denominada "de protección integral" porque establece:

a) los principios, derechos y garantías;

b) el sistema y los órganos administrativos de protección y articulación a nivel nacional y federal, destinados a la promoción, prevención, asistencia, protección, resguardo y restablecimiento de los derechos; y

c) las medidas a llevar a cabo para que los menores de edad alcancen el goce efectivo de los derechos y garantías establecidos en ella.

El artículo $3^{\circ}$ determina el significado que para esta ley tiene el "principio del interés superior del niño": la máxima satisfacción, integral y simultánea de los derechos y garantías reconocidos en esta ley”. Además, por tratarse de un concepto de contenido indeterminado, establece pautas a las que deberá ajustarse el juez para su configuración en el caso concreto. Entre otros criterios, fija algunos que implican la aplicación del principio de autonomía progresiva en el ejercicio de sus derechos: el derecho a ser oídos y a que su opinión sea tenida en cuenta; el respeto a su edad, grado de madurez, capacidad de discernimiento y demás condiciones personales.

El último párrafo del artículo 3 da una pauta hermenéutica concluyente para resolver conflictos entre los derechos e intereses de los menores de edad frente a otros 
derechos e intereses igualmente legítimos de personas adultas: deben prevalecer los derechos de los niños.

En sintonía con el sistema de reconocimiento de derechos, garantías y autonomía progresiva dispuesto en la CDN y en la ley 26061, el Código Civil y Comercial de la Nación recepta la comunidad de principios entre la Constitución, el Derecho Público y el Derecho Privado, que se proyecta en la tutela de los niños. (Ley 26994, Fundamentos del Anteproyecto)

Se ha sustituido en el CCC, la tradicional denominación "patria potestad" por "responsabilidad parental", para desvincularla de su sentido literal de potestad paterna. Autorizada doctrina considera injustificado este cambio, ya que la denominación "patria potestad", por sus orígenes remotos y su recepción social, excedía el mero marco de su sentido literal e individualizaba la institución en sus verdaderos alcances (Medina, 2014, p. 15). No obstante, los redactores del CCC han preferido realizar el cambio de denominación, para poner énfasis en el compromiso con el que deben ser ejercidos los derechos y deberes que se establecen en protección del hijo, para su desarrollo y formación integral. También consideraron conveniente la nueva terminología porque la noción de responsabilidad parental, según ellos, permite visualizar a esta institución como una función de colaboración, orientación, acompañamiento e, incluso, contención, instaurada en beneficio de la persona menor de edad. Y, para armonizar el instituto con otras modificaciones legislativas sobre el matrimonio, se cambió la expresión "padres" por "progenitores".

El significado de la expresión "responsabilidad parental”, está dado en el artículo 638 del CCC de la siguiente manera:
Artículo 638. Responsabilidad parental. Concepto. La responsabilidad parental es el conjunto de deberes y derechos que corresponden a los progenitores sobre la persona y bienes del hijo, para su protección, desarrollo y formación integral mientras sea menor de edad y no se haya emancipado.

El CCC ratifica en diferentes normas, como ya indicamos, los pilares de la regulación jurídica de la minoridad fijados en la CDN y en la ley 26061: "el interés superior del niño", "la autonomía progresiva”, y el "derecho a ser oído y a que su opinión sea tenida en cuenta". A modo de ejemplo, el artículo 639 los fija como rectores del 
ejercicio de la responsabilidad parental; y los artículos 113 y 707 los contemplan para los procesos judiciales en los que esté involucrado un niño.

Artículo 639. Principios generales. Enumeración. La responsabilidad parental se rige por los siguientes principios:

a) el interés superior del niño;

b) la autonomía progresiva del hijo conforme a sus características psicofísicas, aptitudes y desarrollo. A mayor autonomía, disminuye la representación de los progenitores en el ejercicio de los derechos de los hijos;

c) el derecho del niño a ser oído y a que su opinión sea tenida en cuenta según su edad y grado de madurez.

Artículo 113. Audiencia con la persona menor de edad. Para el discernimiento de la tutela, y para cualquier otra decisión relativa a la persona menor de edad, el juez debe: a) oír previamente al niño, niña o adolescente; b) tener en cuenta sus manifestaciones en función de su edad y madurez; c) decidir atendiendo primordialmente a su interés superior.

Artículo 707. Participación en el proceso de personas con capacidad restringida y de niños, niñas y adolescentes. Las personas mayores con capacidad restringida y los niños, niñas y adolescentes tienen derecho a ser oídos en todos los procesos que los afectan directamente. Su opinión debe ser tenida en cuenta y valorada según su grado de discernimiento y la cuestión debatida en el proceso.

Al establecer los "deberes de los progenitores" respecto del hijo, el CCC en el artículo 646, menciona en el inc. a) las obligaciones fundamentales de cuidado y satisfacción de necesidades vitales — alimento, vivienda, educación—; en el b) el tener en cuenta las necesidades específicas según sus características psico-físicas, aptitudes y desarrollo madurativo. También incluye en el inc. e), el deber de facilitar la comunicación del niño con sus parientes y seres queridos; y en el inc. f) el de representarlo y administrar sus bienes. En lo atinente al ejercicio de los derechos del menor de edad reafirma en el 
inc. c) el deber de los padres de oír y tener en cuenta la opinión del hijo, respetar su derecho a participar en su proceso educativo y en lo concerniente a sus derechos personalísimos; y en el inc. d) fija la obligación de orientarlo y guiarlo en el ejercicio efectivo de sus derechos.

En definitiva, el CCC no sólo realiza un cambio de denominación. Al reemplazar la noción de "patria potestad" por la de "responsabilidad parental" adapta esta institución a las exigencias de la CDN, y se adhiere a las tendencias dominantes en el Derecho Comparado que plantean la regulación del vínculo entre padres e hijos de manera horizontal.

\section{Regulación de los derechos personalísimos}

En el presente apartado, en primer lugar, abordaremos la noción de "derechos de la personalidad" e individualizaremos sus características. Posteriormente pasaremos a examinar las normas que tutelan los derechos personalísimos en general, que son aplicables también a los menores de edad, aunque, como veremos en el siguiente apartado, resultan insuficientes para la adecuada protección de sus derechos, debido a su situación de vulnerabilidad.

Los derechos personalísimos — también denominados derechos de la personalidad - son aquellos derechos subjetivos esenciales que, por ser inherentes a la naturaleza humana, corresponden a todo ser humano en cuanto tal, desde su nacimiento hasta su muerte, y que le permiten desenvolverse en la vida social, de acuerdo con su dignidad. En doctrina se identifican como tales al derecho a la vida, a la integridad corporal, a la libertad, al honor, a la intimidad, a la imagen y a la identidad.

La Constitución de la Nación Argentina (CNA) de 1853, si bien ya protegía algunos derechos personalísimos de manera expresa, con la reforma constitucional de 1994, que incorporó en el art. 75 inc. 22, determinados Tratados, Pactos y Convenciones internacionales de derechos humanos, esos derechos quedaron ratificados y los que estaban salvaguardados de manera implícita, fueron explicitados. En estas normas internacionales, entre los que se destacan la Declaración Universal de los Derechos Humanos de 1948, el Pacto Internacional de Derechos Civiles y Políticos de 1966, la Convención Americana sobre Derechos Humanos (Pacto de San José de Costa Rica) de 1969 y la Convención sobre los Derechos del Niño de 1989, están tutelados todos los derechos personalísimos. 
El Código Civil y Comercial de la Nación, teniendo en cuenta la incorporación a la Constitución del derecho supranacional de derechos humanos — cuya reglamentación infraconstitucional corresponde al Código Civil—, establece un régimen sistemático de los derechos de la personalidad.

Los denominados "Derechos y Actos Personalísimos" se encuentran regulados en el Capítulo 3, del Título I, del Libro I. El capítulo comienza con el artículo 51 cuyo acápite "Inviolabilidad de la persona humana" establece que "la persona humana es inviolable". Se consagra de este modo, lo que la Corte Suprema de Justicia de la Nación ha afirmado en reiterados fallos:

El hombre es eje y centro de todo el sistema jurídico y en tanto fin en sí mismo - más allá de su naturaleza trascendente — su persona es inviolable y constituye el valor fundamental con respecto al cual los restantes valores tienen siempre carácter instrumental (Bahamondez, Marcelo s/medida cautelar, 1993).

El artículo finaliza estableciendo que "en cualquier circunstancia tiene derecho al reconocimiento y respeto de su dignidad".

Resulta congruente que se reconozca en primer lugar la dignidad de la persona humana, porque justamente en ella se cimentan los derechos personalísimos que se tutelan a continuación. Dicho en otras palabras, la dignidad es una cualidad de todo ser humano, por el hecho de ser tal, que fundamenta los derechos inherentes a su naturaleza.

Afirmar que la persona humana posee dignidad significa que ontológicamente, es decir, sustancialmente, tiene un valor intrínseco, no dependiente de factores externos, por el que es titular de derechos inherentes a su naturaleza, que exigen el respeto de los demás. Precisamente por eso, la salvaguarda jurídica de los derechos de la personalidad busca garantizar el goce de su dignidad.

La incorporación del concepto de dignidad dentro del derecho privado refuerza la protección de la persona, y reproduce uno de los principios constitucionales informadores del ordenamiento jurídico de nuestro país que está en consonancia con el derecho comparado e internacional. En definitiva, la dignidad de la persona humana es uno de los principios centrales de todo el ordenamiento jurídico argentino y así lo reconoce el nuevo CCC. 
Seguidamente, el artículo 52 contempla el supuesto de daño a ciertos derechos de la personalidad, y determina sus consecuencias: la posibilidad de reclamar la prevención y reparación de los perjuicios sufridos. Es decir que la disposición, no contempla la faz positiva del ejercicio y goce del derecho, sino la dimensión negativa que es la potestad de excluir a terceros de la intromisión o afectación de los derechos personalísimos mencionados. Enumera algunos que la doctrina autoral y judicial considera del ámbito de la integridad espiritual: intimidad, honor, imagen e identidad (Saux, 2014, p. 279); y deja sin mencionar otros de importancia capital, como el derecho a la vida, a la integridad física y a la libertad. De todos modos, estos derechos que tienen rango constitucional, implícitamente están abarcados por la formulación abierta de la norma, al agregar al final "o que de cualquier modo resulte menoscabada en su dignidad personal". No cabe duda, que las amenazas o lesiones a la vida, la integridad física y a la libertad, lo son. Por eso, se puede afirmar que la enumeración no es taxativa, sino que refiere algunos ejemplos.

Por otra parte, el artículo expresamente establece la posibilidad de accionar mecanismos judiciales de prevención o de tutela inhibitoria del daño futuro y previsible en relación con los derechos personalísimos. Esto es de vital importancia teniendo en cuenta que una vez que se lesiona este tipo de derechos, el daño es irreparable, y lo único viable es recibir un resarcimiento económico como compensación por el daño padecido.

Si bien el artículo reseñado habla de las lesiones a "la intimidad personal y familiar", sin definirlas, el artículo 1770, ubicado en la Sección 9a "Supuestos especiales de responsabilidad", ejemplifica conductas violatorias de la intimidad, repitiendo en gran medida el texto del art. 1071bis del Código Civil derogado. En efecto, el artículo 1770 protege el derecho subjetivo a la privacidad, proscribiendo dos conductas: la intromisión arbitraria y la perturbación de la intimidad. Además, describe de manera enunciativa algunas modalidades de ataque: publicación de fotos, imágenes o retratos, difusión de correspondencia, mortificación en las costumbres o sentimientos. En estos o similares casos, las acciones que posee el damnificado son dos: el cese e indemnización del daño en curso, y la indemnización y publicación de la sentencia si el daño se consumó. La publicidad de la sentencia condenatoria forma parte de la reparación plena o integral del daño ocasionado a la intimidad.

La protección alcanza a todas las personas físicas vivas; el ejercicio de la acción es de carácter privado y no se transmite a los herederos. Pero, los sucesores pueden invocar un daño propio por la lesión a la intimidad del muerto (Galdos, 2015, p. 642). 
En cuanto al factor de atribución, conforme al artículo 1721 del CCC, salvo previsión expresa en contrario, sólo puede obligarse a resarcir el daño causado cuando pudiere ser atribuido a dolo o culpa del autor. Pero, es conveniente señalar que, si bien la regla para responder civilmente es la exigencia de culpa o dolo, el Código consagra un gran número de supuestos en los que expresamente establece el carácter objetivo como factor de atribución. Por ejemplo, en las obligaciones de resultado (art. 1723), en la regulación de la responsabilidad por el hecho de terceros: actos involuntarios (art. 1750), responsabilidad del principal (art. 1753), responsabilidad de los padres (art. 1754), etc. Y en doctrina se sostiene que cuando la intromisión en la vida privada proviene de medios de comunicación el factor de atribución es objetivo — conforme al artículo 1757— es decir, basado en el riesgo, genéricamente considerado, en sus variantes riesgo-creado y riesgo-beneficio o riesgo de empresa (Pizarro, 2006, p.165). El fundamento de esta posición se encuentra en la convicción de que la actividad periodística constituye una actividad riesgosa. En este sentido, es evidente que la actividad informativa ha sufrido enormes transformaciones. Actualmente la realizan grandes grupos empresarios económicamente poderosos, que utilizan plataformas de difusión combinadas y medios sofisticados de captación y transmisión de imágenes e información. Estas empresas informativas, movidas por el fin de lucro y la necesidad de transmitir con rapidez noticias que capten la atención de sus potenciales usuarios, en ocasiones, difunden hechos sin previamente haberlos comprobado, generando daños a los derechos personalísimos de los involucrados (Reyna, 2014, p. 340).

El derecho a la imagen, que se extiende a la voz, en armonía con lo propiciado por la doctrina nacional, se encuentra protegido en el artículo 53 del CCC, que determina la ilicitud de la captación y/o la reproducción no consentida de la imagen y de la voz, y enumera las situaciones en las que no se requiere el consentimiento de la persona para su captación y/o reproducción.

El CCC establece en el artículo 55 el principio general de disponibilidad limitada de los derechos de la personalidad, sin perjuicio de regular supuestos específicos en otras partes y en leyes especiales. En este sentido, el Código recepta una premisa indiscutida en doctrina, acerca de que los derechos personalísimos, por tratarse de derechos subjetivos que tienen por objeto manifestaciones que hacen a la esencia misma de la persona, están fuera del comercio, no pueden ser objeto de transmisión hacia otro sujeto de forma alguna y tampoco puede renunciarse a su ejercicio, o consentir su vulneración 
por un tercero. Por ser parcialmente disponibles, una persona puede: firmar un contrato por el que autoriza la captación y difusión de su imagen para una campaña publicitaria; decidir participar en una pelea de boxeo o de lucha libre disponiendo de su integridad física; prestar su consentimiento para formar parte de un reality show disponiendo de su derecho a la intimidad, etc. En estos casos, si sólo están afectados bienes personales y no otros intereses por los que el Estado debe velar, el consentimiento del sujeto cuyos derechos están involucrados, es válido. Aquí no hay renuncia a tales derechos sino el ejercicio de ciertas facultades (Rivera, 1994, p. 51).

Los límites a la disponibilidad de estos derechos están dados por la ley, la moral o las buenas costumbres. En el CCC — al igual que en el anterior - la remisión a la moral y a las buenas costumbres, como límite a la autonomía de la voluntad, es reiterada, lo que lo convierte en un verdadero estándar jurídico. ${ }^{4}$ Por último, el artículo establece tres reglas que son consecuencia del principio de disponibilidad parcial de los derechos de la personalidad:

a) el asentimiento debe ser realizado de modo expreso. De este modo, ante su lesión, no puede alegarse consentimiento tácito del titular del derecho.

b) la determinación de su existencia es de interpretación restrictiva. Esto significa que debe respetarse la finalidad para la que el sujeto prestó su consentimiento.

c) la disposición es libremente revocable, mientras el acto de disposición no se haya llevado a cabo.

Nada se dice sobre si corresponde el resarcimiento en caso de que dicha retracción produzca un daño. Salvo en los casos que por ley se establezca lo contrario, parece razonable inferir que la posibilidad de revocar el consentimiento, en todo momento, hace viable que la contraparte sólo pueda reclamar por los gastos que generó el asentimiento anterior. Pero, si quien revoca su consentimiento lo hace de manera intempestiva y sin

\footnotetext{
${ }^{4}$ A modo de ejemplo podemos citar: En relación con el ejercicio abusivo del derecho el art.10 dispone que "se considerará tal el que contraría los fines del ordenamiento jurídico o el que excede los límites impuestos por la buena fe, la moral y las buenas costumbres". En el ámbito contractual al reconocer la libertad de las partes para contratar el art. 958 establece: "Las partes son libres para celebrar un contrato y determinar su contenido, dentro de los límites impuestos por la ley, el orden público, la moral y las buenas costumbres". En estos supuestos el consentimiento del sujeto será inválido.
} 
justificación, y provoca un daño, conforme a los artículos 1716 y 1717 del CCC, deberá repararlo (Fissore, 2015, p. 169).

Los artículos del CCC que acabamos de examinar resultan aplicables a los menores de edad, en cuanto son personas humanas. Se reconoce la potestad de excluir a terceros de la intromisión o afectación de los derechos a la intimidad y a la imagen; y se otorga la facultad de ejercerlos disponiendo parcialmente de ellos. Además, se individualizan las circunstancias en las que no se requiere el consentimiento de la persona para la captación o reproducción de su imagen o su voz. Pero, nada se dice específicamente sobre los menores de edad. En consecuencia, para determinar los alcances de las atribuciones de los representantes legales y de los niños para decidir sobre sus derechos personalísimos, deberemos tener en cuenta la protección específica que surge del ordenamiento jurídico y del resto de disposiciones sobre autonomía progresiva que abordaremos en los siguientes apartados.

\section{Protección reforzada del derecho a la intimidad, honor e imagen}

El niño, al ser persona y sujeto de derecho, como ya hemos señalado, posee los mismos derechos de la personalidad y goza de las mismas garantías de protección legal que la persona que ha alcanzado los 18 años. Pero por tratarse de un ser humano en proceso de desarrollo y formación, por su falta de madurez, se encuentra en una situación de vulnerabilidad. Por esa razón, la tutela normativa que es adecuada para las personas mayores de edad, resulta insuficiente para la defensa de sus derechos y así lo reconoce el plexo normativo aplicable, que le otorga una protección específica. En este sentido, remarcamos lo dicho al examinar la $\mathrm{CDN}$, en su preámbulo: que el niño, por su falta de madurez física y mental, necesita protección y cuidado especiales, incluso la debida protección legal, tanto antes como después del nacimiento.

a) La Convención sobre los Derechos del Niño protege en el art. 16 el derecho a la intimidad del menor frente a injerencias arbitrarias o ilegales, mencionando aspectos concretos: su vida privada, su familia, su domicilio, su correspondencia. También tutela su honor, y determina que el niño tiene derecho al amparo legal.

$\mathrm{Al}$ abordar los derechos de los niños en conflicto con la ley, la CDN, contempla el derecho a la privacidad al determinar en el artículo 40, inc. 2, vii) que los Estados partes garantizarán "que se respetará plenamente su vida privada en todas las fases del procedimiento". 
b) El Pacto Internacional de Derechos Civiles y Políticos, en su artículo 14, último párrafo, determina que "toda sentencia en materia penal o contenciosa será pública, excepto en los casos en que el interés de menores de edad exija lo contrario, o en las actuaciones referentes a pleitos matrimoniales o a la tutela de menores".

c) La ley 26061 en el Título II, "Principios, derechos y garantías" reconoce en el art. 10 el derecho de los NNA a su privacidad personal y familiar; y en el art. 22 el derecho a que se respete su dignidad, reputación e imagen. En este último artículo se determina la prohibición de dar a conocer datos, informaciones o imágenes que permitan identificar al niño, de manera directa o indirecta, a través de medios de comunicación o publicaciones, si no cuentan con su consentimiento y el de sus representantes legales, cuando sean lesivos de su dignidad o reputación, o dañen su intimidad personal o familiar. Y, el decreto nacional 415/2006 reglamentario de la ley 26061, dispone que se incluyen entre los datos e informaciones cuya difusión prohíbe el art. 22, los referidos a su grupo familiar, su vivienda, su escuela, su apodo o sobrenombre y todo otro que permita identificarlo directa o indirectamente. Además, establece que, aunque medie el consentimiento de los niños y sus representantes legales, cuando el contenido de la exposición, difusión y/o divulgación resulte manifiestamente contraria al interés superior del niño, no podrá desarrollarse. Por lo tanto, en el caso de que se trate de información y/o imágenes que menoscaben la dignidad o reputación del menor, por ser contrarios a su interés superior, el consentimiento del niño y/o de sus representantes legales, no será causal de justificación, ni por lo tanto tampoco de exclusión del carácter ilegítimo de la intromisión, y los medios de comunicación serán civilmente responsables por el perjuicio que pudieran ocasionar.

d) La Ley 20056 sobre "Publicidad de hechos referidos a menores de edad" (1972) prohíbe la difusión de noticias referentes a menores de edad involucrados en delitos o contravenciones o que hayan sido víctimas de ellos, o que estén abandonados o en peligro moral o material. Asimismo, prohíbe con ocasión de esa publicidad, exhibirlos o hacer públicos sus antecedentes personales o familiares que permitan identificarlos. A su vez, quedan exceptuados de dicha prohibición cuando las informaciones sean difundidas o autorizadas por los órganos judiciales o administrativos competentes en el orden nacional o provincial.

Del examen de las normas específicas protectoras de los derechos a la intimidad, al honor y a la imagen del menor de edad, surge con claridad la mayor intensidad de la 
tutela, fundada, como hemos señalado, en la situación de persona en desarrollo. Este amparo legal fortalecido se traduce, en que en ninguna circunstancia puede darse información de un niño que permita directa o indirectamente identificarlo, ni con el consentimiento suyo, ni el de sus representantes legales, y ni siquiera cuando el menor estuviera involucrado en una noticia de interés público, si es lesiva de su intimidad, honor y/o imagen.

\section{Legitimados para actuar frente a las lesiones a la intimidad, al honor y a la imagen del niño}

Los derechos de la personalidad de contenido espiritual del niño, como hemos reseñado, gozan de una tutela legal específica y reforzada respecto de la de los mayores de edad. En este apartado exploraremos las normas pertinentes a fin de determinar qué personas están legitimadas para accionar los mecanismos legales previstos para evitar un daño potencial, o para restablecer el goce de los derechos del menor de edad cuando han sido lesionados.

El ejercicio de los derechos de los niños que no cuentan con edad y grado de madurez suficiente se realiza por medio de sus representantes legales, que son sus padres o el tutor que se les haya designado (CCC, art.101, b.). Esta previsión legal busca proteger al menor representado. Pero, podría suceder que la actuación de sus representantes, en el ámbito del ejercicio de los derechos personalísimos de contenido espiritual, sea contrario al superior interés del menor. En este sentido, la tutela reforzada de los derechos del menor de edad, permite ampararlo incluso frente a la voluntad de sus representantes legales (Antón, 2017, p. 54). También podría ocurrir que la propia acción del niño, o de un tercero, sea lesiva de dichos derechos y sus progenitores no actuaran para hacerlas cesar para restablecer así, la intimidad, el honor y/o la imagen lesionados. En estos casos, en pro del "superior interés del niño", deben actuar los organismos estatales de protección de la niñez, con carácter subsidiario para suplir la inactividad de los progenitores, tutores o guardadores investidos de representación. Y el Ministerio Público, por las prerrogativas que el art. 103 del CCC le otorga, podría incluso actuar de manera principal cuando los derechos de los niños están comprometidos y sus representantes no actúan; o en situaciones en las que carecen de representación legal y es necesario proveer la representación. Por otra parte, si se trata de menores que carecen de representación o teniéndola están en situación de riesgo o abandono — casos de niños privados de forma 
temporal o permanente de su medio familiar o cuyo interés exigió que se lo saque de él一, el Estado está compelido a actuar, en cumplimiento del deber de otorgar su protección, disponiendo las medidas tutelares previstas en los artículos 33 -medidas de protección integral de derechos - y 39 -medidas excepcionales — de la ley 26061.

Además, como hemos visto, el sistema tutelar estatal está previsto no sólo para ser activado cuando se viola un derecho, sino también, ante la amenaza de su lesión (Ley 26061, art 33, parr.1). En este sentido, en los casos en los que el derecho a la intimidad, al honor y/o a la imagen de un menor de edad están en conflicto, por ejemplo, con el ejercicio del derecho a la información de los periodistas, el Derecho aplicable permite solicitar acciones preventivas tendientes a evitar la difusión de noticias cuyo contenido pueda potencialmente lesionar la intimidad de un niño.

En conclusión, sin perjuicio de las acciones de las que sean titulares los representantes legales del menor, frente a un menoscabo de la privacidad del niño, realizada, por ejemplo, por un medio de comunicación, también ante la inacción de sus progenitores o tutores, el Ministerio Público podría actuar de oficio o a instancia del propio menor o de cualquier persona interesada, física o jurídica, sea esta pública o privada. Como podemos apreciar, estos remedios procedentes conforme al CCC, permiten hacer efectivo el principio que debe regir toda decisión que involucra a un menor de edad que es el "interés superior del niño".

\section{Derechos personalísimos y autonomía progresiva}

Hemos considerado la regulación de los derechos personalísimos en general, analizamos la especial protección de los derechos a la intimidad, al honor y a la imagen de los menores de edad, e individuamos quiénes son los sujetos legitimados para solicitar medidas judiciales tendientes a evitar o reparar el daño a estos derechos.

En este apartado exploraremos cómo se conjugan la responsabilidad parental y la autonomía progresiva del niño en el ejercicio de los derechos de la personalidad, según se trate de derechos personalísimos de contenido material o espiritual. Con ese objetivo, analizaremos las nociones de capacidad de ejercicio, de autonomía progresiva y de competencia para abordar seguidamente los respectivos artículos del CCC. El estudio de las normas del Código lo dividiremos en dos subapartados: en el primero examinaremos los párrafos del art. 26 que regulan expresamente el ejercicio de los derechos de la personalidad de dimensión material: derechos a la vida y a la integridad física; en el 
segundo subapartado consideraremos el ejercicio de los derechos de contenido espiritual: derecho a la intimidad y a la imagen, que exigirá una interpretación armónica de diferentes artículos del CCC, ya que no existen normas que determinen edades para su ejercicio.

La capacidad es la aptitud que el ordenamiento jurídico reconoce a las personas para ser titulares de derechos y deberes jurídicos, y para el ejercicio de las facultades que emanan de esos derechos o el cumplimiento de las obligaciones que implican dichos deberes jurídicos (Rivera y Crovi, 2016, p. 237). Como es sabido, la cualidad referida a la titularidad de derechos se la llama capacidad de derecho o de goce; y a la potestad para ejercer los derechos por sí mismos, se la denomina capacidad de ejercicio o de hecho.

Con relación a la capacidad de ejercicio, es decir, a la aptitud de la persona humana para actuar por sí misma en la vida civil, el CCC, tal como ya hemos señalado, adopta el sistema de autonomía progresiva, que promueve el otorgamiento de aptitud para realizar ciertos actos y tomar algunas decisiones por parte de los menores, no sólo en función de la edad, sino tomando también en consideración, el grado de madurez alcanzado por el niño. De ahí que se le reconoce una mayor capacidad de ejercicio en la medida en que el niño, al desarrollarse física y psíquicamente, va alcanzando un nivel de discernimiento superior. A su vez, y en consonancia con los principios que rigen la responsabilidad parental, los progenitores deben favorecer la autonomía personal de sus hijos, promover sus habilidades y aptitudes, además de respetar sus deseos y preferencias.

Señalamos en párrafos anteriores que los niños son sujetos de derecho que se caracterizan por encontrarse en proceso de crecimiento y desarrollo. La Organización Mundial de la Salud (OMS), al hablar de "desarrollo del niño" hace referencia al despliegue armónico de todas sus potencialidades, abarcando la maduración en los aspectos físicos, cognitivos, lingüísticos, socioafectivos, temperamentales y de motricidad. Y si bien el desenvolvimiento madurativo del niño se da en el tiempo, alcanzar cierta edad no garantiza un determinado grado de desarrollo cognitivo, psicológico y emocional. Por eso los progenitores deben estar atentos, supervisar y acompañar a sus hijos menores de edad en la toma de ciertas decisiones para evitar potenciales perjuicios para el menor.

Como se puede apreciar, el sistema de representación que suple la falta de capacidad de ejercicio del menor de edad no es rígido sino flexible y a mayor autonomía del niño, disminuye la representación de sus progenitores (Yurba, 2011, p. 343). 
La noción de capacidad progresiva suele identificarse con el término competencia. La palabra "competencia" es una traducción literal del inglés competence, concepto que se relaciona con la capacidad mental. Este vocablo es utilizado en doctrina, en el área del ejercicio de los derechos personalísimos (Rivera y Crovi, p. 238).

La competencia y la consiguiente autonomía se va adquiriendo de manera gradual, con la madurez psicológica y cognitiva. Y, se debe evaluar en cada caso concreto, si existe o no dicha competencia, en función del tipo de decisión a tomar. Una persona, puede tener aptitud para decidir sobre ciertos asuntos y carecer de ella para otros. Por eso, como advertimos, para evaluar si el menor está en condiciones de ejercer sus derechos por sí mismo, es preciso analizar si puede o no entender acabadamente aquello que se le dice, cuáles son los alcances de la comprensión, si puede comunicarse, si puede razonar sobre las alternativas y si tiene valores para estar en condiciones de formarse un juicio (Kemelmajer de Carlucci, 2011, p. 130).

Las consideraciones precedentes ponen de manifiesto la vinculación de "la competencia" con "el discernimiento", contemplado en el CCC como requisito constitutivo del acto voluntario. Discernir (del lat. discernere, t.) en su primera acepción significa "distinguir algo de otra cosa, señalando la diferencia que hay entre ellas" (Real Academia Española, 2014). El acto de discernir es un juicio.

Discernir es comprender, desentrañar un sentido a las normas; significa distinguir la diferencia entre los opuestos, como el bien y el mal, lo justo e injusto, lo importante y lo intrascendente, lo verdadero y lo falso, lo necesario y lo prescindible, lo honesto y lo deshonesto; o sea, ser capaz de actuar en función del propio juicio crítico (Highton, 2015, p. 12).

En este sentido, el Código determina que el menor actúa con discernimiento, a partir de la edad de 10 años para los actos ilícitos, y 13 años para los actos lícitos. Así, se considera acto involuntario por falta de discernimiento, el acto ilícito realizado por un menor de diez años y el acto lícito llevado a cabo por un niño que no ha alcanzado los trece. (arts. 260 y 261, b. y c. CCC)

El discernimiento, elemento sustancial de la acción voluntaria, permite evaluar la competencia o capacidad progresiva. Dicho en otras palabras, el grado de discernimiento concreto de una persona es pauta para determinar su aptitud para el ejercicio de derechos personalísimos, por sí mismo o con la asistencia de su representante legal. 
Conforme vimos en páginas precedentes, el artículo 639 del CCC, establece, entre los principios rectores del ejercicio de la responsabilidad parental, la autonomía progresiva del hijo según sus características psicofísicas, aptitudes y desarrollo. Por esa razón, la responsabilidad de los padres se ejercerá de manera diferente, según el superior interés del niño. De tener un total protagonismo en las decisiones sobre el hijo en los primeros años de vida, evolucionará paulatinamente hacia una facultad de supervisión o vigilancia con el objetivo último de facilitarle al hijo el pasaje hacia una completa autodeterminación.

En definitiva, la representación, asistencia y cooperación constituyen tres figuras graduales en función del desarrollo del menor de edad. La representación sustituye la voluntad del niño, la asistencia acompaña su voluntad, prestando una conformidad o asentimiento y, finalmente, en la última figura, la decisión la toma el niño, asentado en la contención y apoyo de sus representantes (Herrera, 2015, p. 276).

Al individualizar a las personas incapaces de ejercicio, el CCC incluye en el artículo 24.b) a quienes "no cuentan con edad y grado de madurez suficiente", con el alcance previsto en la Sección 2 da — arts. 25 a 30 del CCC—, que regula la capacidad de la Persona menor de edad. Así, se constata, como ya indicamos, que el régimen de capacidad de los menores de edad instituido en el CCC no se asienta en condiciones etarias fijas, como en el Código de Vélez Sarsfield, sino que introduce un elemento dinámico y permeable, la "madurez suficiente", que exige desentrañar, si el menor de edad está en condiciones de tomar una decisión razonada en el acto concreto de que se trate en un momento determinado.

El CCC dispone que la mayoría de edad y la consiguiente capacidad de ejercicio en forma plena, se obtiene al cumplir los 18 años. Por lo tanto, el niño, en principio, es incapaz de ejercicio, salvo que posea edad y grado de madurez suficiente para ejercer por sí mismo ciertos actos establecidos por la ley. Seguidamente, introduce una distinción entre los menores de trece años y aquellos que han cumplido esa edad, que los denomina adolescentes.

De la lectura de los artículos que hacen referencia al sistema de autonomía progresiva, cabe inferir que la capacidad progresiva se reserva al ejercicio de derechos personalísimos, y no al de los patrimoniales, ya que la seguridad jurídica requiere que la capacidad e incapacidad para los negocios jurídicos patrimoniales esté basada en franjas de edad rígidas, y en ocasiones, se determine la total interdicción de una persona cuando 
los sistemas de apoyo previstos no serían eficaces para ella. En este sentido, es preciso tener en cuenta que las restricciones a la capacidad de obrar en las relaciones contractuales tienen la finalidad de proteger el patrimonio de aquellas personas que por su falta de desarrollo intelectual o psíquico no están en condiciones de administrarlo o disponer de él. Por esa razón, junto con la capacidad aplicable a las relaciones patrimoniales, el CCC regula los aspectos derivados de la denominada capacidad progresiva o competencia que alude a la posibilidad de investigar el real discernimiento del sujeto para el ejercicio de los derechos inherentes a la persona, de contenido no patrimonial.

La capacidad de ejercicio de los menores de edad, y en especial de los adolescentes, para la realización de actos concretos, está fijada en varios artículos dispersos en el CCC y en otras leyes. A modo de ejemplo, mencionamos el artículo 684 del CCC que se refiere a la aptitud para realizar contratos de escasa cuantía, que la doctrina reconocía, pero no estaba plasmada en la ley.

El CCC, al regular la capacidad de ejercicio de los niños, en consonancia con la CDN, mantiene la responsabilidad y autoridad parental. (CDN, art. 5) En efecto, el artículo 26, primer párrafo, al abordar el ejercicio de los derechos por las personas menores de edad, establece el principio general de que ejercen sus derechos a través de sus representantes legales. Es decir, que la incapacidad se suple con la figura de la representación, conforme ordenan los artículos 100 y 101 del CCC. Y, es importante destacar que, en los asuntos en que están involucrados menores de edad, según establece el artículo 103 del CCC, también gozan de la intervención, del Ministerio Público, un órgano estatal de asistencia y control que tiene por finalidad garantizar la protección y defensa de sus derechos. El Ministerio Público interviene de manera complementaria conjunta - con los representantes necesarios del menor, o principal, en ciertos supuestos previstos por la ley. Su participación es fundamental para la validez de los actos y procedimientos judiciales en los que esté implicado el interés de un niño. Y esto es así porque su rol es esencial para garantizar y asegurar el goce de los derechos de los niños, al brindar un "plus de protección" a los menores de edad.

El artículo 26, párrafo 2do, determina que, en los casos previstos legalmente, si cuentan con edad y grado de madurez suficiente, podrán ejercer los actos por sí mismos. Seguidamente, en el párrafo 3ero, prescribe el derecho a ser oído en procesos judiciales y demás situaciones en las que esté involucrado, así como a participar en las decisiones 
sobre su persona. Conviene precisar que el derecho del menor a ser escuchado supone que el niño tiene discernimiento para dar su opinión en el caso concreto.

Resumiendo lo analizado hasta aquí, el CCC establece el principio general de incapacidad del niño, y un sistema de autonomía progresiva que exige a los progenitores ejercer de manera diferente su responsabilidad parental, teniendo en cuenta las características psicofísicas, aptitudes y desarrollo del hijo. Así, en los primeros años de vida tendrán un total protagonismo en las decisiones que afectan al menor. Pero, a medida en que vaya alcanzando cierto grado de madurez, el niño debe ser oído y su opinión tenida en cuenta, e incluso podrá participar en las decisiones sobre su persona. Y al adquirir cierta edad y madurez suficiente — que se presume al alcanzar la edad legal- el menor puede ejercer por sí mismo los derechos que el ordenamiento jurídico le permite.

A continuación, en los subapartados siguientes nos ocuparemos, como ya advertimos, de las normas que contemplan la autonomía progresiva en el ejercicio de los derechos personalísimos del menor de edad.

\section{Ejercicio de los derechos a la vida y a la integridad física vinculado a la salud}

En los párrafos 4to. y 5to., el art. 26 otorga al adolescente entre los 13 y 16 años, una ampliación de su capacidad de obrar en las cuestiones atinentes al derecho a la salud. $\mathrm{Al}$ regular esta mayor autonomía, el CCC utiliza conceptos jurídicos abiertos y flexibles: alude a tratamientos "invasivos" y "no invasivos" o que "provocan un riesgo grave en su vida o integridad física”. Conviene tener en cuenta que esta ampliación de la capacidad para decidir en materia médica de los menores de edad entre los 13 y 16 años tuvo su origen en el contexto de los debates sobre el acceso de los adolescentes al uso de anticonceptivos sin necesidad del conocimiento y autorización de los padres (Fernández, Herrera y Lamm, 2017), por lo que la extensión que realiza el CCC a "todos los tratamientos médicos" es una derivación que resulta problemática y contradictoria con otras normas. Por ejemplo, podemos citar la Ley $N^{\circ} 26529$ de Derechos del Paciente en su Relación con los Profesionales e Instituciones de la Salud (9/XI/2009). ${ }^{5}$

Por otra parte, aunque se afirme como fundamento de la norma la loable intención de evitar judicializar situaciones que comprometen la salud de personas vulnerables, como son los niños, el autorizarlos a consentir por sí mismos la realización de ciertos actos supuestamente médicos sobre su persona, puede, en la práctica, dejarlos

\footnotetext{
${ }^{5}$ Para un estudio exhaustivo de esta problemática ver Lafferriere (2017).
} 
desprotegidos y sin la asistencia y contención de sus progenitores en edades en las que todavía no poseen la madurez suficiente para discernir, decidir y asumir las consecuencias de sus actos.

El término "invasivo" al que alude el artículo 26, según el Diccionario de la Lengua Española es un adjetivo cuyo significado, "dicho de un procedimiento diagnóstico o terapéutico", es "que obliga a penetrar en el cuerpo mediante una incisión en la piel o a introducir en él un instrumento o material extraño al organismo" (Real Academia Española, 2014).

En doctrina se ha hecho un esfuerzo por identificar cuáles serían tratamientos invasivos y cuáles no (Kemelmajer de Carlucci, Herrera, Lamm y Fernández, 2015, p. 4). Pero, sería deseable que también se tenga en cuenta que algunos tratamientos que entrarían en la categoría de "no invasivos" pueden comprometer el estado de salud del menor que ha cumplido 13 años y, por lo tanto, deberían quedar fuera de su órbita de decisión por sí mismo. Además, en el marco del respeto de los derechos y deberes de los padres, no hay que perder de vista la necesaria armonización del principio de autonomía progresiva con el principio del interés superior del niño para evitar otorgarle el ejercicio por sí mismos de derechos para los cuales, por falta de madurez suficiente, como ya hemos advertido, su decisión podría producir consecuencias perjudiciales para su persona.

Por último, el art. 26, párrafo 6to, estipula que a partir de los 16 años el adolescente es considerado adulto para las decisiones referidas al cuidado de su propio cuerpo. A esta hipótesis normativa la doctrina la llama supuesto de "mayoría de edad anticipada" (Olmo, 2014, p. 82).

En definitiva, según el sistema establecido por el CCC los niños se pueden encontrar en tres situaciones diferentes, según la edad y grado de madurez, al momento de ejercer sus derechos:

a) Hasta los trece años los niños están sujetos a la representación de sus padres, o en su defecto, a la del tutor que se les nombre para la realización de actos jurídicos. A su vez, para la toma de decisiones sobre su persona, tienen derecho a ser oídos y a participar en las decisiones.

b) Entre los 13 y 16 años se presume que los menores tienen competencia para decidir por sí mismos sobre "tratamientos no invasivos", que no comprometan gravemente ni el estado de salud, ni la vida, ni la integridad física. Si la decisión a tomar 
hace referencia a un "tratamiento invasivo" que compromete el estado de salud, la vida o la integridad física, deben concurrir de manera conjunta el consentimiento del adolescente y el de sus progenitores. Y en caso de desacuerdo, teniendo en cuenta la opinión médica al respecto y el interés superior del niño, el juez competente resolverá el conflicto.

c) A partir de los 16 años el adolescente tiene capacidad plena, porque el CCC lo asimila al mayor de edad, para las decisiones sobre el cuidado de su propio cuerpo.

Coherente con el artículo 26 reseñado, el artículo 32 prevé que la restricción a la capacidad para determinados actos puede ser dictada judicialmente a partir de los trece años y, para esos casos, el CCC establece el sistema de apoyos y salvaguardias. Excepcionalmente, en los casos de pérdida total de discernimiento, el juez puede restringir totalmente la capacidad de ejercicio y nombrar un curador.

\section{Ejercicio de los derechos a la intimidad y a la imagen}

Cabe precisar que, en este apartado dedicado a los derechos personalísimos de contenido espiritual, no mencionamos al honor, porque el derecho al honor de un niño, es considerado de indisponibilidad absoluta (Hernández, 2012, p. 99).

En el caso de un niño, en principio, conforme al artículo 26 del CCC ya considerado, la disposición del derecho a la intimidad y a la imagen solo puede ser realizada por los representantes legales antes de haber cumplido la edad de 13 años, que es cuando la ley presume que alcanza el discernimiento para realizar actos lícitos (art. 261 CCC). A su vez, teniendo en cuenta el sistema de autonomía progresiva instaurado por nuestro ordenamiento jurídico, cuando los progenitores realicen acciones que impliquen la disposición de la intimidad de un hijo, este previamente deberá ser oído y su opinión tenida en cuenta, dando por sentado que dicha decisión previamente debe respetar el interés superior del niño.

En cuanto al menor que ha cumplido los 13 años — adolescente en la terminología del CCC - , considerando los artículos atinentes a la capacidad de ejercicio del menor de edad - especialmente los arts. 24, 25, 26-y los referidos a la responsabilidad parental —en particular, los arts. 638, 639 y 646- no se aprecian diferencias respecto del niño que no alcanzó esa edad sobre el ejercicio de su derecho a la intimidad y a la imagen. Al respecto, según el artículo 646 inciso c) del CCC, los padres tienen el deber de "respetar el derecho del niño y adolescente a ser oído y a participar en su proceso educativo, así como en todo lo referente a sus derechos personalísimos". Ahora bien, este artículo es 
impreciso: ¿quién es el que participa en la toma de decisiones referidas a los derechos personalísimos, los progenitores o sus hijos? Navarro Floria sostiene que "hubiera sido más razonable reconocer a los padres el derecho de guiar al niño en el aprendizaje progresivo de su ejercicio, como resultaría del inciso d) del mismo artículo 646, pero dejando en claro quién tiene la última palabra” (Navarro Floria, 2016, p. 25).

Por nuestra parte, entendemos que "participar" se aplica a los niños y es deber de los padres promover esa participación. Asimismo, teniendo en cuenta que el niño alcanza el discernimiento para realizar actos lícitos a partir de los 13 años, y a esa edad se le reconoce capacidad de ejercicio para tomar decisiones por sí mismo respecto de tratamientos médicos "no invasivos", proponemos que en una futura reforma del Código, se contemple expresamente la edad requerida para tomar decisiones vinculadas con la disposición de la intimidad y de la imagen del adolescente: con la asistencia de sus progenitores o tutores, sólo con su apoyo y colaboración, y por sí mismo. En este sentido, Lafferriere ve conveniente implementar un sistema de edades fijas para habilitar actos de las personas menores de edad sin la intervención de sus padres, buscando una inteligente y gradual articulación de las distintas maneras de participar de los niños, desde el derecho a ser escuchado hasta la toma de decisiones por sí mismos (Lafferriere, 2019). Consideramos que, en el caso del menor que ya ha cumplido los 13 años, conforme a la regulación plasmada en el CCC, para disponer de su intimidad y de su imagen, es requerido que su consentimiento sea acompañado del de sus progenitores, mediante el instituto de la asistencia.

\section{Conclusiones}

Nos propusimos examinar la especial protección de los derechos personalísimos del niño y la manera en que se plasma el principio de autonomía progresiva en el ámbito del ejercicio de los derechos de la personalidad del menor de edad, poniendo especial énfasis en los derechos a la intimidad y a la imagen. Con ese fin, estudiamos las normas constitucionales y legales referida a los derechos de los niños, niñas y adolescentes, que nos permitió individualizar los principios informadores del sistema, entre los que se destacan "el principio del interés superior del niño" como criterio para determinar el contenido de cualquier decisión en la que esté involucrado un menor de edad, y "el

principio de autonomía progresiva" en el ejercicio de los derechos. Abordamos la 
regulación de los derechos personalísimos en general, y la protección reforzada de los derechos a la intimidad, al honor y a la imagen del menor de edad.

De este estudio, surgió diáfano el imperativo legal de que cuando se quiere dar a conocer información de interés público en la que esté involucrado un niño, y esta puede potencialmente lesionar su intimidad, honor y/o imagen, debe hacerse de tal modo que no sea posible su identificación. Posteriormente, examinamos la legitimación para reclamar medidas judiciales tendientes al cese en caso de lesiones actuales o potenciales a los derechos personalísimos a la intimidad, al honor y/o a la imagen del niño. En estos supuestos, en ejercicio de la responsabilidad parental, los progenitores son los legitimados para actuar. Pero si ellos no lo hacen, deben actuar los organismos estatales de protección de la niñez, con carácter subsidiario para suplir la inactividad de los progenitores, tutores o guardadores investidos de representación. Y el Ministerio Público, por las prerrogativas que el art. 103 del CCC le otorga, podría incluso actuar de manera principal cuando los derechos del menor están comprometidos y sus representantes no actúan, o son ellos mismos los que con su conducta lesionan los derechos de su hijo.

Seguidamente, analizamos las normas que contemplan la autonomía progresiva en el ejercicio de los derechos del menor de edad establecidas en el CCC. Constatamos que este principio, promueve el otorgamiento de aptitud para realizar ciertos actos y tomar algunas decisiones por parte de los menores, en función de la edad y el grado de madurez alcanzado por el niño. A su vez, los progenitores en el ejercicio de su responsabilidad parental deben favorecer la autonomía personal de sus hijos, promover sus habilidades y aptitudes, además de respetar sus deseos y preferencias. Dentro de este apartado, examinamos el ejercicio de los derechos a la vida y a la integridad física vinculados a la salud. En este ámbito cobra gran importancia el artículo 26 del CCC que otorga al adolescente entre los 13 y 16 años, una ampliación de su capacidad de obrar pudiendo decidir por sí mismo sobre "tratamientos no invasivos"; y a partir de los 16 años el adolescente es considerado adulto para las decisiones referidas al cuidado de su propio cuerpo. Pensamos que el otorgarles capacidad para consentir por sí mismos la realización de ciertos actos médicos sobre su persona, aunque se consideren "no invasivos", puede, en la práctica, dejarlos desprotegidos y sin la asistencia y contención de sus progenitores en edades en las que todavía no poseen la madurez suficiente para discernir, decidir y asumir las consecuencias de sus actos. 
Al estudiar el ejercicio de los derechos a la intimidad y a la imagen constatamos que no se aprecian diferencias entre los menores que han cumplido los 13 años respecto de quienes no alcanzaron esa edad sobre el ejercicio de sus derechos a la intimidad y a la imagen. Los padres tienen el deber de respetar el derecho del niño a ser oído y a participar en su proceso educativo, así como en todo lo referente a sus derechos personalísimos. Creemos que el "participar" se aplica a los niños y es deber de los padres promover esa participación. Por otra parte, el Código no establece edades para el ejercicio de los derechos personalísimos de contenido espiritual. Por esa razón, teniendo en cuenta que el niño alcanza el discernimiento para realizar actos lícitos a partir de los 13 años, y a esa edad el CCC le reconoce capacidad de ejercicio para tomar decisiones por sí mismo respecto de tratamientos médicos "no invasivos", proponemos que en una futura reforma del CCC, se contemple expresamente la edad requerida para tomar decisiones vinculadas con la disposición de la intimidad y de la imagen del adolescente: con la asistencia de sus progenitores o tutores, sólo con su apoyo y colaboración, y por sí mismo. En la actual regulación plasmada en el CCC consideramos que cumplidos los 13 años su consentimiento debe ir acompañado del de sus progenitores, mediante el instituto de la asistencia.

\section{Referencias}

Antón, M. E. (2017). Derechos y responsabilidades en una comunicación con perspectiva en Derechos Humanos. Misiones, Argentina: Ed. Universitaria, Universidad Nacional de Misiones.

Fernández, S. E., Herrera, M., y Lamm, E. (2017). El principio de autonomía progresiva en el campo de la salud. Diario La Ley del 28/11/2017. Buenos Aires, Argentina: La Ley.

Fissore, D. M. (2015). Los derechos de la personalidad espiritual en el Código Civil y Comercial de la Nación. Revista de Derecho Privado y Comunitario, 2015-3, 169-170.

Galdos, J. M. (2015). Comentario al artículo 1770. En R. Lorenzetti (Dir.), Código Civil y Comercial de la Nación Comentado, t. 8, (pp. 642-646). Santa Fe, Argentina: RubinzalCulzoni.

Hernández, M. d. M. (2012). Internet y el derecho al honor de los menores. IUS. Revista del Instituto de Ciencias Jurídicas de Puebla, 6(29), 99-102.

Herrera, M. (2015). Comentarios a los artículos 594 a 723. En R. Lorenzetti (Dir.), Código Civil y Comercial de la Nación Comentado, t. 4 (pp. 09-661). Santa Fe, Argentina: RubinzalCulzoni.

Highton, E. I. (2015). Capacidad de los menores de edad. Revista de Derecho Privado y Comunitario, 2015-3, 195-282. 
Kemelmajer de Carlucci, A. (2011). Dignidad y autonomía progresiva de los niños. Revista de Derecho Privado y Comunitario, 2010-3, 123-144.

Kemelmajer de Carlucci, A., Herrera, M., Lamm, E., y Fernández, S. (2015). El principio de autonomía progresiva en el Código Civil y Comercial. Algunas reglas para su aplicación. Recuperado de http://www.saij.gob.ar/aida-kemelmajer-carlucci-principio-autonomiaprogresiva-codigo-civil-comercial-algunas-reglas-para-su-aplicacion-dacf150461-201508-18/123456789-0abc-defg1640-51fcanirtcod

Lafferriere, J. N. (2017). ¿Solos con su cuerpo? Capacidad de los adolescentes para actos médicos en Argentina. Revista de Derecho, 16, 67-100.

Lafferriere, J. N. (2019). Las convenciones sobre los derechos del niño y sobre los derechos de las personas con discapacidad y sus proyecciones en relación con la regulación civil de la capacidad de ejercicio. Reflexiones a partir del derecho argentino. Revista de Derecho Privado, 38, 51-82. Recuperado de https://revistas.uexternado.edu.co/index.php/derpri/article/view/6296

Medina, G. (2014). La responsabilidad parental en el Código Civil y Comercial de la Nación. Revista de Derecho de Familia y de las Personas, 10, 15-31.

Navarro Floria, J. G. (2016). Los derechos personalísimos. Buenos Aires, Argentina: El Derecho.

Olmo, J. P. (2014). Capacidad. En G. Medina y J. C. Rivera (dirs.), Código Civil y Comercial de la Nación Comentado, t. 1, (pp. 74-115). Buenos Aires, Argentina: La Ley.

Organización Mundial de la Salud (s. f.). Salud de la madre, del recién nacido, del niño y del adolescente. Desarrollo. Recuperado el 18/06/2019 de http://www.who.int/maternal_child_adolescent/topics/child/development/es/

Pizarro, D. (2006). La responsabilidad por riesgo de empresa y los medios masivos de comunicación. Revista de Derecho de Daños, 3, 165-167.

Real Academia Española. (2014). Discernir. Diccionario de la lengua española (23 ed.). Recuperado de https://dle.rae.es/discernir?m=form

Real Academia Española. (2014). Invasivo. Diccionario de la lengua española (23a ed.). Recuperado de https://dle.rae.es/invasivo?m=form

Reyna, C. A. (2014). Responsabilidad por entrometimiento en la vida privada en el Código de 1871 y en el Proyecto de Código Civil y Comercial de 2012. Revista de Derecho de Daños, 2, 293-346.

Rivera, J. C. (1994). Actos de disposición de los derechos de la personalidad. Revista de Derecho Privado y Comunitario, 6, 89-113.

Rivera, J. C., y Crovi, L. D. (2016). Derecho Civil. Parte General. Buenos Aires, Argentina: Abeledo-Perrot.

Saux, E. I. (2014). Derechos y actos personalísimos. En R. Lorenzetti (Dir.), Código Civil y Comercial de la Nación Comentado, t. 1 (pp. 279-282). Santa Fe, Argentina: RubinzalCulzoni. 
Yurba, G. (2011). La representación y asistencia de las personas menores de edad, incapaces y con capacidad restringida. El rol del Ministerio Público. Revista de Derecho Privado y Comunitario, 3, 329-360.

\section{Normas}

Ley N ${ }^{\circ}$ 10903. Patronato de Menores. Boletín Oficial de la República Argentina. Buenos Aires: 27 de octubre de 2019.

Ley $\mathrm{N}^{\circ}$ 20056. Prensa. Prohibición de la difusión o publicidad de hechos referidos a menores de edad. Boletín Oficial de la República Argentina. Buenos Aires: 5 de abril de 1973.

Ley $\mathrm{N}^{\circ}$ 23313. Pacto internacional de derechos civiles y políticos. Boletín Oficial de la República Argentina. Buenos aires: 13 de mayo de 1986.

Ley $\mathrm{N}^{\circ}$ 23849. Convención sobre los Derechos del Niño. Boletín Oficial de la República Argentina. Buenos Aires: 23 de octubre de 1990.

Ley $\mathrm{N}^{\circ} 24430$. Constitución de la Nación Argentina (sancionada en 1853 con las reformas de los años 1860, 1866, 1898, 1957 y 1994). Boletín Oficial de la República Argentina. Buenos Aires: 23 de agosto de 1994.

Ley $\mathrm{N}^{\circ}$ 26061. Protección integral de derechos de niñas, niños y adolescentes. Boletín Oficial de la República Argentina. Buenos Aires: 26 de octubre de 2005.

Ley $\mathrm{N}^{\circ}$ 26529. Derechos del Paciente en su Relación con los Profesionales e Instituciones de la Salud. Boletín Oficial de la República Argentina. Buenos Aires: 20 de noviembre de 2009. Modificada por la Ley 26.742. Boletín Oficial de la República Argentina. Buenos Aires: 24 de mayo de 2012.

Ley N ${ }^{\circ}$ 26994. Código Civil y Comercial de la Nación. Boletín Oficial de la República Argentina, Buenos Aires: 8 de octubre de 2014.

\section{Fallos}

Corte Suprema de Justicia de la Nación. Fallos, 316:479: Bahamondez, Marcelo s/ medida cautelar (06-04-1993). Diario El Derecho (t. 153-254). Buenos Aires: El Derecho.

\section{Contribución autoral}

a) Concepción y diseño del trabajo; b) Adquisición de datos; c) Análisis e interpretación de datos;

d) Redacción del manuscrito; e) revisión crítica del manuscrito.

M. B. N. ha contribuido en a, b, c, d, e.

\section{Editor científico responsable}

Dr. Pablo Rodríguez Almada 